Guido J. Reiss*

\title{
A cyclic $\mathrm{I}_{10}{ }^{2-}$ anion in the layered crystal structure of theophyllinium pentaiodide, $\mathrm{C}_{7} \mathrm{H}_{9} \mathrm{I}_{5} \mathrm{~N}_{4} \mathrm{O}_{2}$
}

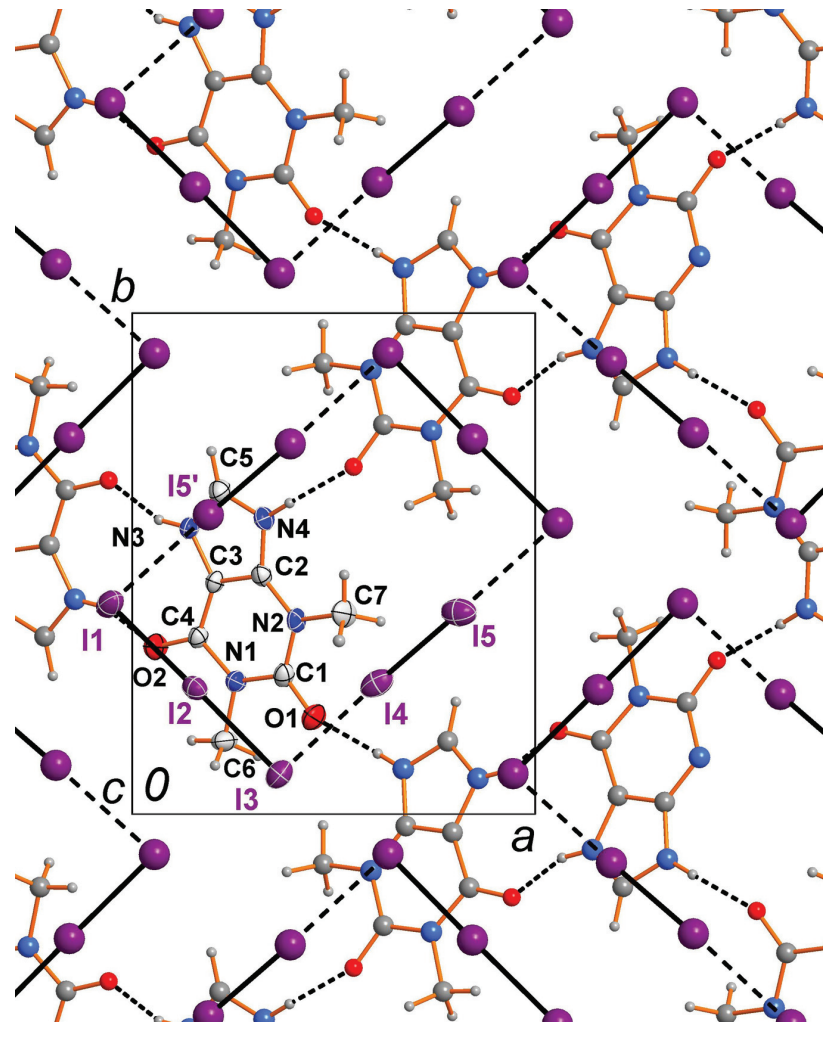

https://doi.org/10.1515/ncrs-2019-0082

Received January 26, 2019; accepted March 25, 2019; available online May 3, 2019

\section{Abstract \\ $\mathrm{C}_{7} \mathrm{H}_{9} \mathrm{I}_{5} \mathrm{~N}_{4} \mathrm{O}_{2}$, monoclinic, $P 2_{1} / c$ (no. 14), $a=9.46793(10) \AA$, $b=11.58276(12) \AA, \quad c=16.41497(18) \AA, \quad \beta=100.844(1)^{\circ}$, $Z=4, V=1768.00(3) \AA^{3}, R_{g t}(F)=0.0306, w R_{\text {ref }}\left(F^{2}\right)=0.0728$, $T=130(2) \mathrm{K}$.}

\section{CCDC no.: 1905427}

The molecular structure is shown in the figure. Table 1 contains crystallographic data and Table 2 contains the list of the atoms including atomic coordinates and displacement parameters.

\footnotetext{
*Corresponding author: Guido J. Reiss, Institut für Anorganische Chemie und Strukturchemie, Lehrstuhl II: Material- und Strukturforschung, Heinrich-Heine-Universität Düsseldorf, Universitätsstrasse 1, D-40225 Düsseldorf, Germany, e-mail: reissg@hhu.de
}

Table 1: Data collection and handling.

\begin{tabular}{|c|c|}
\hline Crystal: & Black shiny block \\
\hline Size: & $0.34 \times 0.27 \times 0.21 \mathrm{~mm}$ \\
\hline Wavelength: & Mo $K \alpha$ radiation $(0.71073 \AA)$ \\
\hline$\mu$ : & $8.80 \mathrm{~mm}^{-1}$ \\
\hline Diffractometer, scan mode: & Xcalibur- EOS, $\omega$ \\
\hline$\theta_{\max }$, completeness: & $28.5^{\circ},>99 \%$ \\
\hline$N(h k l)_{\text {measured }}, N(h k l)_{\text {unique }}, R_{\text {int }}:$ & $52671,4465,0.030$ \\
\hline Criterion for $I_{\mathrm{obs}}, N\left(h k l_{\mathrm{gt}}\right.$ : & $I_{\text {obs }}>2 \sigma\left(I_{\text {obs }}\right), 4173$ \\
\hline$N(\text { param })_{\text {refined }}:$ & 174 \\
\hline Programs: & $\begin{array}{l}\text { Diamond [1], CrysAlis }{ }^{\text {PRO }}[2] \text {, } \\
\text { SHELX [3-5] }\end{array}$ \\
\hline
\end{tabular}

Table 2: Fractional atomic coordinates and isotropic or equivalent isotropic displacement parameters $\left(\AA^{2}\right)$.

\begin{tabular}{lrrrr}
\hline Atom & $\boldsymbol{x}$ & $\boldsymbol{y}$ & $\boldsymbol{z}$ & $\boldsymbol{U}_{\text {iso }} / \boldsymbol{U}_{\text {eq }}$ \\
\hline I1 & $-0.05603(4)$ & $0.41770(3)$ & $0.25049(2)$ & $0.03655(10)$ \\
I2 & $0.15381(3)$ & $0.25151(2)$ & $0.32685(2)$ & $0.02540(8)$ \\
I3 & $0.36362(3)$ & $0.07971(3)$ & $0.41151(2)$ & $0.03031(9)$ \\
I4 & $0.60290(4)$ & $0.26148(3)$ & $0.51239(2)$ & $0.03868(10)$ \\
I5 & $0.80523(5)$ & $0.40502(3)$ & $0.60464(3)$ & $0.04772(11)$ \\
O1 & $0.4504(3)$ & $0.1977(3)$ & $0.20058(18)$ & $0.0233(6)$ \\
O2 & $0.0587(3)$ & $0.3354(3)$ & $0.02188(18)$ & $0.0211(6)$ \\
N1 & $0.2572(3)$ & $0.2679(3)$ & $0.1107(2)$ & $0.0178(6)$ \\
N2 & $0.4066(3)$ & $0.3900(3)$ & $0.2066(2)$ & $0.0176(6)$ \\
N3 & $0.1428(4)$ & $0.5726(3)$ & $0.0963(2)$ & $0.0183(6)$ \\
H3 & $0.072(7)$ & $0.592(5)$ & $0.066(4)$ & $0.037(16)^{\star}$ \\
N4 & $0.3278(4)$ & $0.5924(3)$ & $0.1963(2)$ & $0.0191(7)$ \\
H4 & $0.393(7)$ & $0.624(6)$ & $0.226(4)$ & $0.045(18)^{\star}$ \\
C1 & $0.3766(4)$ & $0.2808(4)$ & $0.1746(2)$ & $0.0179(7)$ \\
C2 & $0.3208(4)$ & $0.4786(3)$ & $0.1740(2)$ & $0.0158(7)$ \\
C3 & $0.2051(4)$ & $0.4651(3)$ & $0.1108(2)$ & $0.0151(7)$ \\
C4 & $0.1638(4)$ & $0.3550(3)$ & $0.0757(2)$ & $0.0165(7)$ \\
C5 & $0.2179(4)$ & $0.6469(4)$ & $0.1477(3)$ & $0.0203(8)$ \\
H5 & 0.197936 & 0.725295 & 0.149980 & $0.024^{*}$ \\
C6 & $0.2273(5)$ & $0.1494(4)$ & $0.0797(3)$ & $0.0272(9)$ \\
H6A & 0.149744 & 0.150503 & 0.032647 & $0.041^{*}$ \\
H6B & 0.200953 & 0.102392 & 0.122624 & $0.041^{*}$ \\
H6C & 0.311695 & 0.117929 & 0.063472 & $0.041^{*}$ \\
C7 & $0.5251(5)$ & $0.4044(4)$ & $0.2774(3)$ & $0.0304(10)$ \\
H7A & 0.527870 & 0.483025 & 0.296131 & $0.046^{*}$ \\
H7B & 0.614326 & 0.385626 & 0.260806 & $0.046^{*}$ \\
H7C & 0.510762 & 0.354048 & 0.321557 & $0.046^{*}$ \\
\hline & & & &
\end{tabular}

Ә Open Access. ( 2019 Guido J. Reiss, published by De Gruyter. (c) BY License. 


\section{Source of material}

All chemicals were obtained from commercial sources and used as purchased. The Raman spectra were measured using a Bruker MULTIRAM spectrometer (Nd: YAG-laser at $1064 \mathrm{~nm}$; InGaAs detector) with an apodized resolution of $8 \mathrm{~cm}^{-1}$ in the region of $4000-70 \mathrm{~cm}^{-1}$. The title compound was synthesized by dissolving $0.18 \mathrm{~g}$ ( $1 \mathrm{mmol})$ theophylline and $0.25 \mathrm{~g}$ (1 mmol) diiodine in $1 \mathrm{~mL}$ of $57 \%$ aqueous hydroiodic acid. Heating to $\sim 350 \mathrm{~K}$ yielded a dark colored solution, which produced black, block crystals upon slow cooling to room temperature.

\section{Experimental details}

A single crystal of the title compound was directly selected from the mother liquor and rapidly transferred into the cold gas-stream ( $T=146 \mathrm{~K})$ of the Xcalibur four-circle diffractometer equipped with an EOS detector [2]. An absorption correction (Gaussian method) was applied [2]. The structure solution and the refinement were successfully carried out using the SHELX program system [3-5]. Hydrogen atoms which are involved in hydrogen bonds were refined freely. All other hydrogen bonds were added using a riding model with fixed $U_{\text {iso }}$ parameters. The maximum residual peak of $3.63 \mathrm{e}^{-3}$ and the deepest hole of $-2.15 \mathrm{e}^{-3}$ are found 0.79 and $0.68 \AA$, respectively, from atom $\mathrm{I} 5$.

\section{Comment}

Nowadays polyiodides (in the $19^{\text {th }}$ century periodides [6]) are defined as the anionic parts of salt structures that fulfil the general formula $\mathrm{I}_{2 \mathrm{~m}-\mathrm{n}}^{\mathrm{n}-}(n=2-5, m=$ integer $)$. Nearly all polyiodides are constructed of $\mathrm{I}^{-}, \mathrm{I}_{3}{ }^{-}$and $\mathrm{I}_{2}$ units. These ions and the $\mathrm{I}_{2}$ molecule tend to form extended motifs by means of halogen bonds [7-10]. The triiodide monoanion has been considered as the simplest polyiodide species. Extended theoretical studies on the phenomenon of halogen bonding led to a deeper understanding of its occurrence [11-13]. Polyiodides are of interest not only because of their structures, but also because of recently reported applications. Short-chain polyiodides play a key role in the charge-transfer processes of the classical dye-sensitized solar cells $[14,15]$. Moreover, polyiodide species may be used as ambipolar zinc electrolytes [16] and promoted the development of optimized lithiumiodine redox batteries [17]. Apart from possible applications there is still an academic interest in the synthesis of new, tailored polyiodides using cationic templates whose lengths and shapes may influence the topology of the polyiodide anions [18-20]. We have shown that semi-flexible cations [21-23] and heterocyclic cations like pyridinium derivatives [24, 25] or naturally occurring base like nicotine [26] or caffeine [27] are excellent tectons for the synthesis of polyiodide containing salts. Many structures with the formal $\mathrm{I}_{5}{ }^{-}$anion are known
$[9,19,26]$, but to the best of our knowledge, only one dimeric cyclic $\left(\mathrm{I}_{5}{ }^{-}\right)_{2}$ anion has been reported [28] until now.

From the reaction of theophylline (systematic name: 1,3dimethyl-3,7-dihydro- $1 H$-purine-2,6-dione) with hydroiodic acid in the presence of excess iodine, black, shiny, block crystals of the title compound were obtained. The crystalline material loses its excess of iodine slowly at ambient conditions.

The asymmetric unit of the title compound consists of one $\mathrm{N}$-protonated theophyllinium cation, one triiodide anion and one iodine molecule residing on general positions in the space group $P 2_{1} / c$. The geometric parameters of the title cation are very similar to those known from the literature (Tab. 2) [29].

In the title structure each theophyllinium cation donates and accepts two hydrogen bonds to three (crystallographically dependent) adjacent cations via its $\mathrm{N}-\mathrm{H}$ and $\mathrm{C}=\mathrm{O}$ functional groups, respectively (see the figure). These hydrogen bonds lead to wavy layers. Six symmetry-related cations form annulated ring motifs (see the figure). The NH...O hydrogen-bond parameters are (N . . O distances of 2.671(4) $\AA$ and 2.725(4) A) in the expected ranges [27].

Between adjacent cationic, hydrogen-bonded theophyllinium layers the polyiodide anions are intercalated (see the figure). Each polyiodide $\mathrm{I}_{10}{ }^{2-}$ moiety consists of two pentaiodide fragments, which show I-I distances which are in the typical range of single bonds to strong secondary interac-

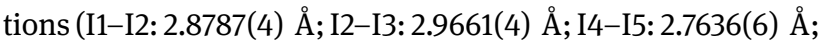

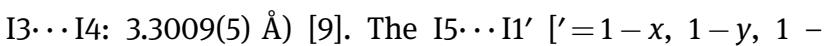
$z$ ] distance of 3.6582(6) $\AA$ is in the typical range of weaker I. . I interactions, but significantly shorter than any van der Waals distances in the various scales [30]. In the structure of the known cyclic $\mathrm{I}_{10}{ }^{2-}$, the four secondary $\mathrm{I}$... I distances are crystallographically constrained and are at 3.441(1) $\AA$ [28] fairly accurate within the arithmetic mean of the distances derived for the title structure. Further significant I. . I I interactions can be ruled out as the corresponding iodine to iodine distances ( $>3.9 \AA$ ) are very close the sum of the van der Waals radii. The angles within the $\mathrm{I}_{10}{ }^{2-}$ dianion are in accord with the expectations (I2-I1-I5': 77.41(1) ${ }^{\circ}$; I2-I3-I4: 98.22(1) ${ }^{\circ}$; I4-I3-I1-I5 $\left.{ }^{\prime}\left[^{\prime}=1-x, 1-y, 1-z\right]\right)$. Finally, it is worth mentioning that the hydrogen-bonded layers show a wavy shape fitting excellently with the needs of the neighboring polyiodide anions.

Within the Raman spectrum of the title compound the lines which are characteristic for the triiodide anion [31] are found at $108(v s)$ and $145(v s) \mathrm{cm}^{-1}$. For the solid phase of elemental iodine a I-I valence vibration is generally observed at $180 \mathrm{~cm}^{-1}$ [32]. The Raman spectrum of the title compound shows a very strong line at $172 \mathrm{~cm}^{-1}$. As the iodine molecule is weakly connected to two neighboring halogen bond donors, 
a small shift of this line to lower wave numbers compared to elemental iodine is expected.

Acknowledgements: The authors thanks E. Hammes and M. Wyshusek for technical support. Support by the Ministry of Innovation, Science and Research of North-Rhine Westphalia and the German Research Foundation (DFG) for financial support is gratefully acknowledged (Xcalibur diffractometer; INST 208/533-1, project No. 162659349). Funding by the open access fund of the Heinrich-Heine-Universität Düsseldorf is also gratefully acknowledged.

\section{References}

1. Brandenburg, K.: DIAMOND. Visual Crystal Structure Information System. Ver. 4.5.2, Crystal Impact, Bonn, Germany (2018).

2. Oxford Diffraction: CrysAlis ${ }^{\mathrm{PRO}}$, (version 1.171.33.42), Oxford Diffraction Ltd., Oxford, UK (2009).

3. Sheldrick, G. M.: A short history of SHELX. Acta Crystallogr. A64 (2008) 112-122.

4. Sheldrick, G. M.: Crystal structure refinement with SHELXL. Acta Crystallogr. C71 (2015) 3-8.

5. Hübschle, C. B.; Sheldrick, G. M.; Dittrich, B.: ShelXle: a Qt graphical user interface for SHELXL. J. Appl. Crystallogr. 44 (2011) 1281-1284.

6. Tilden, W. A.: On the periodides of some of the organic bases. J. Chem. Soc. 18 (1865) 99-105.

7. Tebbe, K.-F.: Polyhalogen cations and polyhalide anions, in Homoatomic rings, chains and macromolecules of main-group elements. (Eds.: H. Wood, F. Belger), Elsevier, Amsterdam (1977) 551-606.

8. Blake, A. J.; Devillanova, F. A.; Gould, R. O.; Li, W. S.; Lippolis, V.; Parsons, S.; Radek, C.; Schröder, M.: Template selfassembly of polyiodide networks. Chem. Soc. Rev. 27 (1998) 195-205.

9. Svensson, P. H.; Kloo, L.: Synthesis, structure, and bonding in polyiodide and metal iodide-iodine systems. Chem. Rev. 103 (2003) 1649-1684.

10. Kloo, L.; Rosdahl, J.; Svensson, P. H.: On the intra- and intermolecular bonding in polyiodides. Eur. J. Inorg. Chem. 2002 (2002) 1203-1209.

11. Politzer, P.; Murray, J. S.: Halogen bonding: an interim discussion. ChemPhysChem 14 (2013) 278-294.

12. Politzer, P.; Murray, J. S.; Clark, T.: $\sigma$-Hole bonding: a physical interpretation, in halogen bonding I. Vol. 358 (Eds.: P. Metrangolo, G. Resnati), Springer International Publishing, (2015) 19-42.

13. Thirman, J.; Engelage, E.; Huber, S. M.; Head-Gordon, M.: Characterizing the interplay of Pauli repulsion, electrostatics, dispersion and charge transfer in halogen bonding with energy decomposition analysis. Phys. Chem. Chem. Phys. 20 (2018) 905-915.

14. O’Regan, B.; Grätzel, M.: A low-cost, high-efficiency solar cell based on dye-sensitized colloidal $\mathrm{TiO}_{2}$ films. Nature 353 (1991) 737-739.

15. Correa-Baena, J.-P.; Abate, A.; Saliba, M.; Tress, W.; Jacobsson, T. J.; Grätzel, M.; Hagfeldt, A.: The rapid evolution of highly efficient perovskite solar cells. Energy Environ. Sci. 10 (2017) 710-727.

16. Li, B.; Nie, Z.; Vijayakumar, M.; Li, G.; Liu, J.; Sprenkle, V.; Wang, W.: Ambipolar zinc-polyiodide electrolyte for a highenergy density aqueous redox flow battery. Nat. Commun. 6 (2015) 6303.

17. Zhao, Y.; Hong, M.; Bonnet Mercier, N.; Yu, G.; Choi, H. C.; Byon, H. R.: A $3.5 \mathrm{~V}$ lithium-iodine hybrid redox battery with vertically aligned carbon nanotube current collector. Nano Lett. 14 (2014) 1085-1092.

18. Walbaum, C.; Pantenburg, I.; Meyer, G.: Penta-, Hepta- und Oktaiodid-Anionen in Salzen mit Erdalkalimetall-KronenetherKationen. Z. Naturforsch. B65 (2010) 1077-1083.

19. Walbaum, C.; Pantenburg, I.; Junk, P.; Deacon, G. B.; Meyer, G.: Bulky cations and four different polyiodide anions in $\left[\mathrm{Lu}(\mathrm{Db} 18 \mathrm{c} 6)\left(\mathrm{H}_{2} \mathrm{O}\right)_{3}(\mathrm{thf})_{6}\right]_{4}\left(\mathrm{I}_{3}\right)_{2}\left(\mathrm{I}_{5}\right)_{6}\left(\mathrm{I}_{8}\right)\left(\mathrm{I}_{12}\right)$. Z. Anorg. Allg. Chem. 636 (2010) 1444-1446.

20. Peuronen, A.; Rinta, H.; Lahtinen, M.: N $\cdots$ I halogen bonding supported stabilization of a discrete pseudo-linear $\left[\mathrm{I}_{12}\right]^{2-}$ polyiodide. CrystEngComm 17 (2015) 1736-1740 and references cited therein.

21. van Megen, M.; Reiss, G. J.: $\mathrm{I}_{6}{ }^{2-}$ Anion composed of two asymmetric triiodide moieties: a competition between halogen and hydrogen bond. Inorganics 1 (2013) 3-13.

22. van Megen, M.; Jablonka, A.; Reiss, G. J.: Synthesis, structure and thermal decomposition of a new iodine inclusion compound in the 2,2-dimethylpropane-1,3-diamine $/ \mathrm{HI} / \mathrm{I}_{2}$ system. Z. Naturforsch. B69 (2014) 753-760.

23. Reiss, G. J.: Two iodine-rich (dimethylphosphoryl) methanaminium iodides. Z. Kristallogr. CM 232 (2017) 789-795.

24. Reiss, G. J.; Leske, P. B.: The twinned crystal structure of bis(4aminopyridin-1-ium) iodide triiodide, $\mathrm{C}_{20} \mathrm{H}_{28} \mathrm{I}_{8} \mathrm{~N}_{8}$. Z. Kristallogr. NCS 229 (2014) 452-454 and references cited.

25. Reiss, G. J.; van Megen, M.: Two new polyiodides in the 4,4'bipyridinium diiodide/iodine system. Z. Naturforsch. B67 (2012) 5-10.

26. Reiss, G. J.: $I_{5}-$ polymers with a layered arrangement: synthesis, spectroscopy, and structure of a new polyiodide salt in the nicotine $/ \mathrm{HI} / \mathrm{I}_{2}$ system. Z. Naturforsch. B70 (2015) 735-740.

27. Merkelbach, J.; Majewski, M. A.; Reiss, G. J.: Crystal structure of caffeinium triiodide - caffeine (1/1), $\mathrm{C}_{16} \mathrm{H}_{21} \mathrm{I}_{3} \mathrm{~N}_{8} \mathrm{O}_{4}$. Z. Kristallogr. NCS 233 (2018) 941-944.

28. Wieczorrek, C.: Isolierte $\mathrm{I}_{10}{ }^{2-}$-Ringe, ein neues Strukturelement in der Polyiodid-Chemie. Acta Crystallogr. C56 (2000) 1082-1084.

29. Buist, A. R.; Kennedy, A. R.; Manzie, C.: Four salt phases of theophylline. Acta Crystallogr. C70 (2014) 220-224.

30. Hu, S.-Z.; Zhou, Z.-H.; Xie, Z.-X.; Robertson, B. E.: A comparative study of crystallographic van der Waals radii. Z. Kristallogr. CM 229 (2014) 517-523.

31. Deplano, P.; Ferraro, J. R.; Mercuri, M. L.; Trogu, E. F.: Structural and Raman spectroscopic studies as complementary tools in elucidating the nature of the bonding in polyiodides and in donor $I_{2}$ adduct. Coord. Chem. Rev. 188 (1999) 71-95.

32. Congeduti, A.; Nardone, M.; Postorino, P.: Polarized Raman spectra of a single crystal of iodine. Chem. Phys. 256 (2000) 117-123. 